\title{
DEBATES
}

\section{Cibercultura, juventude e heteronormatividade: ativismo e resistência no Facebook}

\author{
Cyberculture, youth and heteronormativity: activism and resistance \\ on Facebook
}

\section{Dilton Ribeiro do Couto Junior Maria Luiza Magalhães Bastos Oswald}

\section{Resumo}

O texto mostra o protagonismo e o ativismo político que um grupo de jovens internautas estabelece nas dinâmicas comunicacionais do Facebook. Esse grupo é constituído de jovens que não se identificam com o modelo da heterossexualidade e buscam, através do diálogo em rede, contestar questóes de gênero e sexualidade sintonizadas com a ótica heteronormativa. Fruto de tese de doutorado recentemente concluída, o estudo reconheceu que a mediação das práticas sociais ciberculturais pode potencializar a participação política e social juvenil. Desenvolvido na perspectiva dialógica e alteritária bakhtiniana, o estudo nos permitiu perceber que o ciberespaço é um espaço privilegiado para que os jovens exerçam hoje a liberdade de expressão, exerçam a possibilidade de falar, de ouvir e de manifestar-se politicamente pelo que acreditam, promovendo a possibilidade de resistência frente à heteronormatividade a partir de ativismos que se constituem dinamicamente através da potência do diálogo em rede.

\section{Palavras-chave}

Cibercultura; Juventudes; Heteronormatividade; Resistência; Política.

\begin{abstract}
The text shows the political activism and engagement in which a group of young Internet users establishes on the communicational dynamics of Facebook. This group is composed of young people who do not identify with the model of heterosexuality and seek, through Internet dialogue, to contest issues of gender and sexuality that are in harmony with the optic of heteronormativity. Part of a doctoral dissertation recently concluded, the study recognized that the mediation of cybercultural social practices could strengthen the political and social participation of the youth. Developed in the bakhtinian perspective of dialogism and otherness, the study allowed us to understand cyberspace as a privileged space for young people today to exercise freedom of expression., to exercise the possibility to speak, to listen and to express themselves politically by what they believe, promoting the possibility of resistance against heteronormativity throughout activisms which are dynamically constituted by the power of Internet dialogue.
\end{abstract}

\section{Keywords}

Cyberculture; Youth; Heteronormativity; Resistance; Policy. 


\section{Introdução}

A dinamicidade e a agilidade com as quais os jovens se organizam na rede mostram o quanto as conversas online mobilizam pessoas geograficamente dispersas em torno de interesses comuns. No contexto das dinâmicas ciberculturais, os internautas, uns com os outros, consomem e produzem diversos tipos de informaçáo, corroborando os princípios fundamentais da sociedade da informação: "emitindo, na produção de conteúdo, conectando, em processos coletivos e colaborativos, produzindo inteligências coletivas e alterando as condiçóes de vida, reconfigurando a cultura e a vida social" (LEMOS, 2007, p. 48, grifos nossos). Diversas interfaces digitais gratuitas propiciam a interconexão entre os sujeitos, que passam de meros receptores de dados informacionais a colaboradores ativos de suas próprias narrativas, produzidas e compartilhadas na relação com o outro através do diálogo em rede. $\mathrm{O}$ conceito de rede é aqui entendido "como todo fluxo e feixe de relaçôes entre seres humanos e objetos técnicos. Nessa híbrida relação, todo e qualquer signo pode ser produzido e socializado no e pelo ciberespaço" (SANTOS, 2005, p. 197). Essa especificidade da rede, ao agregar informações produzidas e compartilhadas por internautas de todas as regióes do planeta, a torna um campo empírico rico para a pesquisa em educação.

A cibercultura nasce de uma apropriação tecnológica que vem modificando as relações cotidianas dos sujeitos (LEMOS, 2013) e descentralizando os meios de comunicação massivos. Longe de ser compreendida como a cultura do ciberespaço, a cibercultura permite a rica troca na internet, principalmente a partir das redes sociais digitais. Os processos comunicacionais dos quais os jovens participam na contemporaneidade revelam que as experiências mediadas pelas tecnologias digitais em rede reconfiguram a forma como recebem informaçóes e adquirem conhecimento. Rosa, Ferreira e Oswald (2010) destacam que a constituição de novas sociabilidades através das formas com as quais os jovens interagem com os meios midiáticos certamente merece um olhar mais atento pelo campo da educação, principalmente quando o contexto sociocultural brasileiro já vem apresentando fortes traços de um fazer político nas redes sociais da internet com a participação juvenil.

A "liberaçáo da palavra", um dos princípios da cibercultura, torna os internautas capazes de romper com o polo da emissão, produzindo e compartilhando novos conteúdos e, dessa forma, promovendo novas ressignificaçóes. De acordo com Lemos (2010), a "liberação da palavra" permite a qualquer pessoa "consumir, produzir e distribuir informação sob qualquer formato em tempo real e para qualquer lugar do mundo" (LEMOS, 2010, p. 25, grifos nossos). Caminhando nessa mesma 
direção, Castells (2013) aponta que as redes sociais da internet são "espaços de autonomia, muito além do controle de governos e empresas - que, ao longo da história, haviam monopolizado os canais de comunicação como alicerces de seu poder" (CASTELLS, 2013, p. 7). Interagir na rede e em rede traz implicações para as questóes referentes à sociabilidade, à subjetividade, às formas de ensinar e aprender, uma vez que modifica como recebemos informaçóes e adquirimos conhecimento na relação com o outro (SANTAELLA, 2013). Neste sentido é que "os sujeitos do conhecimento precisam ter sua alteridade reconhecida, sentindo-se implicados numa produção coletiva, dinâmica e interativa" (SANTOS, 2002, p. 122).

O presente texto é fruto de pesquisa de doutorado recentemente concluída, cuja centralidade investigativa problematiza a naturalização e normatização do modelo da heterossexualidade. Como procedimento teórico-metodológico da investigação adotou-se a perspectiva dialógica bakhtiniana (BAKHTIN, 2011; AMORIM, 2013; JOBIM E SOUZA e ALBUQUERQUE, 2012) para estabelecer conversas online com um grupo de jovens no Facebook que não se identificam com o modelo heterossexual. $\mathrm{O}$ reconhecimento da alteridade, princípio bakhtiniano da pesquisa em Ciências Humanas, tem sido crucial no estudo em questão para favorecer a constituição de laços entre pesquisador e sujeitos e entre os próprios sujeitos no Facebook, campo empírico do estudo que vem se configurando como lugar de encontro com o outro, permitindo o intercâmbio de histórias e experiências a partir das inúmeras postagens realizadas na referida rede social. Os participantes da investigação não são identificados por seus próprios nomes, mas por pseudônimos com os quais gostariam de ser nomeados e reconhecidos no texto escrito da pesquisa ${ }^{1}$.

Compartilhando uma concepção positiva de juventude e veementemente contrários às diferentes e constantes manifestaçôes de homofobia, nosso objetivo ao redigirmos esse texto foi compartilhar com o leitor o ativismo político exercido pelos jovens pesquisados para contestar questóes de gênero e sexualidade sintonizadas com a ótica heteronormativa. Esta ótica diz respeito à regulação das práticas sexuais, dos desejos, do sexo e do gênero, dentro de uma perspectiva que compreende as categorias binárias masculino e feminino como distintas, complementares e hierarquizadas (COUTO JUNIOR e OSWALD, 2014). A opção por desenvolver o estudo no âmbito das práticas sociais ciberculturais reflete o interesse pela mediação

\footnotetext{
${ }^{1} \mathrm{O}$ primeiro autor deste texto integrou o grupo no Facebook. A presença dele no estudo de campo é justificada pela opção teórico-metodológica do estabelecimento de uma relação de alteridade entre o pesquisador e seus sujeitos. A coautora do artigo é orientadora da pesquisa de doutorado em questão.
} 
que as tecnologias digitais em rede proporcionam na relação comunicacional dos sujeitos. Ao contrário das mídias massivas, nas quais o fluxo da informação se dá na perspectiva "um-todos", nos processos comunicacionais mediados pelas mídias digitais em rede, há a possibilidade da comunicação “todos-todos”. Não há como desconsiderar que as redes digitais vêm se constituindo como espaços privilegiados para que muitos jovens, hoje, exerçam a liberdade de expressão; exerçam a possibilidade de falar e de ouvir, de manifestar-se politicamente pelo que acreditam. Essa riqueza de informaçóes produzidas e compartilhadas pelos internautas através das redes sociais torna o ciberespaço um campo de pesquisa promissor para as diferentes áreas do conhecimento, numa época nitidamente marcada pelos processos comunicacionais digitais.

Se por um lado discursos preconceituosos e discriminatórios difundem-se pela internet, por outro lado, as chamadas "minorias"2 sexuais também se organizam, fortalecem os vínculos sociais e buscam estratégias de resistência a partir do diálogo em rede. Para Santos, "a rede não tem centro, os elementos circulam e se deslocam de acordo com as necessidades e problematizaçóes dos sujeitos" (SANTOS, 2002, p. 118), o que proporciona uma relação de maior liberdade para que compartilhemos nossas indignaçôes, desejos e fantasias com outros internautas. Ainda que não estejam se referindo à internet, as palavras de Gallo e Aspis (2011) nos ajudam a pensar que os usos da rede mundial de computadores também se constituem como práticas centrais na luta contra a dominação, garantindo a liberdade aos sujeitos: "Campo de possíveis aprendizagens, possíveis experimentações, possíveis criaçóes de si mesmo, possíveis mundos. Liberdade mínima, que seja, para que possa haver resistência" (GALLO e ASPIS, 2011, p. 176).

Foucault (2004, p. 277) considera inadequada a afirmação "vocês veem poder por todo lado; então não há lugar para a liberdade” porque o poder não seria um sistema de dominação que tudo controla, sem permitir nenhuma brecha para práticas de liberdade (FOUCAULT, 2004, p. 277). Na citação a seguir, o autor esclarece que as relações de poder, constituintes das relaçóes humanas, são reversíveis e instáveis:

\footnotetext{
2 O termo "minorias" não se refere a uma quantidade numérica, mas a uma qualidade valorativa atribuída por um grupo sobre outro (LOURO, 2008).
} 


\begin{abstract}
Quando se fala de poder, as pessoas pensam imediatamente em uma estrutura política, em um governo, em uma classe social dominante, no senhor diante do escravo etc. Não é absolutamente o que penso quando falo das relações de poder. Quero dizer que, nas relaçóes humanas, quaisquer que sejam elas - quer se trate de comunicar verbalmente [...], ou se trate de relaçóes amorosas, institucionais ou econômicas -, o poder está sempre presente: quero dizer, a relação em que cada um procura dirigir a conduta do outro. São, portanto, relaçóes que se podem encontrar em diferentes níveis, sob diferentes formas; essas relaçôes de poder são móveis, ou seja, podem se modificar, não são dadas de uma vez por todas (FOUCAULT, 2004, p. 276).
\end{abstract}

Foucault (1995) considera que para uma melhor compressão das relações de poder, é cada vez mais necessário uma análise atenta às diferentes formas de resistência pelos sujeitos. Se Castells (2006) caracteriza a internet como tecnologia de liberdade, não seria demais supor também a importância das redes sociais como lócus de resistência. Dessa forma, "se não houvesse possibilidade de resistência - de resistência violenta, de fuga, de subterfúgios, de estratégias que invertam a situação -, não haveria de forma alguma relações de poder" (FOUCAULT, 2004, p. 277). Como refletir sobre essas resistências, que agora também encontraram um espaço promissor e potente no contexto das dinâmicas sociais mediadas pelas tecnologias em rede? Mesmo em países que apresentam governos autoritários responsáveis pelo bloqueamento de determinados sites, proibindo também que diversos conteúdos sejam publicados online, ainda sim os internautas que vivem o terror dessas imposições "respiram na grande conversação da Internet e da diversidade de sítios mundiais o maravilhoso perfume da liberdade" (LEMOS e LÉVY, 2010, p. 99). A possibilidade de customização dos diversos grupos de amigos nas redes sociais da internet cria formas distintas de dialogar na rede, evidenciando o quanto o ativismo vem se beneficiando de novas estratégias com as dinâmicas ciberculturais.

A relação interativa e colaborativa nos processos comunicacionais digitais fornecem os meios para que os internautas expressem descontentamentos diante das notícias veiculadas pelas mídias sobre o cenário político (JENKINS, 2009). As inúmeras insatisfações sociais impulsionam os jovens internautas a propor aspirações nas conversas online, com o desejo de tornar melhor o mundo hoje a partir de reflexôes sobre como o mundo poderia ser. Vale lembrar novamente os dizeres de Jenkins (2009), para quem o povo, "que ganhou poder com as novas tecnologias e vem ocupando um espaço na intersecção entre os velhos e os novos meios de 
comunicação, está exigindo o direito de participar intimamente da cultura" (JENKINS, 2009, p. 53). Esse desejo vem sendo impulsionado pelo interesse dos internautas pela participação ativa e colaborativa que emerge com os diálogos em rede, cuja escrita realizada através da internet se caracteriza por "uma escrita teclada criativa (criando códigos apropriados ao novo suporte), espontânea, em tempo real, interativa. É uma escrita viva, natural [...] dirigida a um ou vários interlocutores" (FREITAS, 2005, p. 1).

Ao criar um grupo no Facebook, os jovens da pesquisa têm à disposição um espaço importante para se expressarem livremente na promoçáo de formas de resistência e engajamento político em torno de discussões que problematizem e coloquem em xeque a heteronormatividade. De acordo com a perspectiva foucaultiana, "a insubordinação, o não-acomodamento, a recusa ao ajustamento são algumas de múltiplas formas que a resistência pode assumir” (LOURO, 2009, p. 137). Somando-se a isso, as múltiplas formas encontradas pelas juventudes contemporâneas de fazer política nas redes sociais vai de encontro com um certo pessimismo nas reflexôes "científicas" que discutem a temática da juventude pelo viés que a reconhece como "fase da vida", inclusive muitas vezes adotando os discursos fragmentados da cultura juvenil que são veiculados nos meios de comunicação de massa.

O sociólogo José Machado Pais (1990) diz que, ao reconhecer a juventude enquanto "fase da vida", definindo-a dentro de termos etários, deixamos de compreender que os jovens encontram-se imersos em um universo diversificado, marcado pelas classes sociais e econômicas, por oportunidades ocupacionais, por diferentes interesses, dentre outros aspectos. Portanto, situar a juventude como "etapa da vida", já tendo cumprido a etapa do ser criança e aguardando a etapa do ser adulto, é desconsiderar o universo social de tantos e diferentes jovens com experiências diversas de vida. $\mathrm{Na}$ compreensão do autor, há jovens solteiros e casados, de diferentes classes sociais, vivendo dentro ou fora da cidade, ocupando as mais diversas profissões e, portanto, "estamos a falar de juventudes em sentido completamente diferente do da juventude enquanto referida a uma fase de vida" (PAIS, 1990, p. 149).

Com o objetivo de articular o conceito de juventude às múltiplas formas de ser e estar no mundo, Dayrell (2003) enfatiza a necessidade do uso do termo no plural: "juventudes". Segundo o autor, esse plural seria uma forma de abarcar a multiplicidade de modos de ser jovem, entendendo-se que o ser humano não se constitui apenas biologicamente, mas também social e culturalmente. 
Pais (1990) comenta ainda que a juventude vem constantemente sendo vista como um problema social, inclusive no âmbito familiar e escolar. Abramo (1997) aponta que questôes sociais como a violência, o uso de drogas, a prostituição e as doenças sexualmente transmissíveis são muitas vezes associadas aos jovens; questóes estas que, dirigidas sobre eles (pela ótica dos adultos), dificilmente são enunciadas por eles. Diante desse contexto, Pais (1990) questiona se o pessimismo das pesquisas "sobre a juventude não será uma ressonância do discurso que atravessa o olhar das geraçôes adultas sobre as geraçóes jovens” (PAIS, 2009, p. 144, grifos nossos). Em outras palavras, o autor chama atenção para o fato de que a visão estereotipada do jovem violento leva à suposição de que a solução para os problemas sociais deve sempre vir do adulto.

Considerando a juventude sob um olhar positivo, entendendo-a como capaz de praticar açôes passíveis de transformar a realidade social, indagamos: como seria possível ressignificar o olhar pessimista sobre uma juventude ainda encarada como problema social, encontrando outras formas de se compreender as práticas juvenis? Em quais espaços seria possível conhecer o protagonismo social das juventudes? $\mathrm{O}$ que os jovens têm a dizer sobre gênero e sexualidade nas redes sociais digitais? E como se apropriar dos processos comunicacionais digitais para buscar formas mais colaborativas, livres e plenas de participação em lutas políticas? Essas são algumas das questôes centrais que norteiam as reflexões do presente texto acerca da participação política juvenil no contexto das práticas sociais ciberculturais.

\section{"Acabei de fazer essa imagem para a manifestação de amanhã. queria a opinião de vocês. curtiram, não curtiram e pq?"3}

Em junho de 2013, inúmeras manifestações ocorreram em diversas regiōes do Brasil e do mundo. No Rio de Janeiro, jovens se apropriaram das redes sociais, como o Twitter e o Facebook, na organização e no agendamento dos horários e locais dos protestos que ocorreram em diversos locais da cidade. As manifestaçóes inicialmente apresentavam como objetivo central lutar contra o aumento de $\mathrm{R} \$ 0,20$ nas passagens de ônibus, mas se fortaleceram e adquiriram maior proporçáo na medida em que outros grupos sociais, com outras demandas, incorporaram novas reivindicaçóes aos protestos que tomaram conta das ruas da "cidade maravilhosa". Os

\footnotetext{
${ }^{3}$ Convite de Jorge, um dos jovens que participam da pesquisa, a um grupo de amigos do Facebook, para que opinassem sobre um cartaz por ele produzido contra a homofobia, que seria utilizado nas manifestaçóes de junho de 2013 no Rio de Janeiro.
} 
movimentos que se espalharam pelo mundo via internet foram motivados pela "humilhação provocada pelo cinismo e pela arrogância das pessoas no poder, seja ele financeiro, político ou cultural, que uniu aqueles que transformaram medo em indignação, e indignação em esperança de uma humanidade melhor" (CASTELLS, 2013 , p. 8). As redes sociais também foram imprescindíveis para que os manifestantes, aqui no Brasil, pudessem se organizar, se comunicar e mobilizar uma quantidade significativa de pessoas em torno de interesses comuns.

As manifestações de junho de 2013 se constituem hoje como um acontecimento recente na história brasileira. Ainda assim, diversos autores que pesquisam os meios de comunicação digitais já publicaram trabalhos focalizando esses protestos no contexto das práticas sociais engendradas pela cibercultura. "Não são os centavos, são nossos direitos" (CASTELLS, 2013, p. 178), descreveu Castells acerca da insatisfação das pessoas nas ruas, que buscavam melhores condiçóes para a educação, saúde, dentre outras reivindicações. Iniciando o seu texto com a pergunta “o que querem essas meninas e esses meninos [nas ruas]?” (PRETTO, 2014, p. 345), Pretto (2014) também refletiu sobre as recentes manifestaçóes populares contra os aspectos políticos e econômicos do país, apontando para a importância das diferentes apropriaçôes das mídias digitais pelas juventudes brasileiras. Além disso, Recuero, Zago e Bastos (2014) discutiram o uso do Twitter durante o período dos protestos e perceberam a necessidade dessa rede social para narrar e mobilizar os internautas sobre os acontecimentos do país. Novamente fazemos nossas as palavras de Castells (2013), para quem concorda que podemos apenas sugerir hipóteses às análises dos recentes movimentos das redes sociais da internet, uma vez que "é cedo demais para construir uma interpretação sistemática, acadêmica, desses movimentos" (CASTELLS, 2013, p. 10, grifos nossos).

Os jovens hoje estão cada vez mais interconectados e com o desejo de contribuir com a produção de conhecimento, alimentando o ciberespaço com informaçóes tecidas colaborativa e dinamicamente, principalmente a partir de mensagens trocadas através de tecnologias digitais móveis e de imagens produzidas e compartilhadas nas redes sociais. Os integrantes que constituem o grupo no Facebook assumiram para si a necessidade de ressignificar seus modos de vida, incorporando experiências de outros internautas para estarem mais próximos a partir de objetivos e interesses comuns. Como nos lembram Lemos e Lévy (2010), 
(...)sempre que podemos produzir com voz livre (liberação do polo da missão), nos organizar, conectar e produzir coisas coletivamente [...], iremos, com certeza, produzir reconfigurações nas instituições culturais, no fazer político, no espaço público, na democracia (LEMOS e LÉVY, 2010, p. 83).

Os modos juvenis de fazer política antenados com a imersão contemporânea na cibercultura fez com que parte desse grupo se mobilizasse nas ruas do Rio de Janeiro frente à indignação com o Projeto de Lei conhecido como "cura gay". De autoria do deputado João Campos (PSDB-GO), esse projeto foi aprovado pela Comissão de Direitos Humanos da Câmara em junho de 2013. Em resposta à sua aprovação, Jorge decidiu criar uma imagem que representasse a liberdade de expressão sexual, indo de encontro às ideologias sociais vinculadas ao projeto "cura gay". Construída de forma colaborativa no Facebook, a imagem foi utilizada durante as manifestaçôes que ocorreram em junho de 2013 na cidade do Rio de Janeiro. Dentro dos princípios interativos das redes sociais, a construção da imagem a seguir tornou possível que cada internauta expressasse "ideias, necessidades, sugestóes, críticas ou qualquer tipo de sentimento" (SANTAELLA, 2013, p. 44), conforme é possível perceber a seguir.

Por intermédio da conversa online, o grupo envolvido nessa atividade foi desconstruindo a expressão CURA GAY, transformando-a, através das inúmeras interferências dos jovens Jorge, Feliciana, Thayane, Rodrigo, Patrick, Nogan, Nectar, Polobio e Dilton, na expressão:

\footnotetext{
${ }^{4}$ Para outras informações sobre o projeto, acesse a reportagem online do Jornal da Globo disponível em: $\quad$ http://g1.globo.com/jornal-da-globo/noticia/2013/06/cura-gay-e-aprovada-pela-comissao-dedireitos-humanos-da-camara.html Acesso em: 21 jun. 2013.
} 
Figura 1 - Cartaz confeccionado no Facebook de forma colaborativa

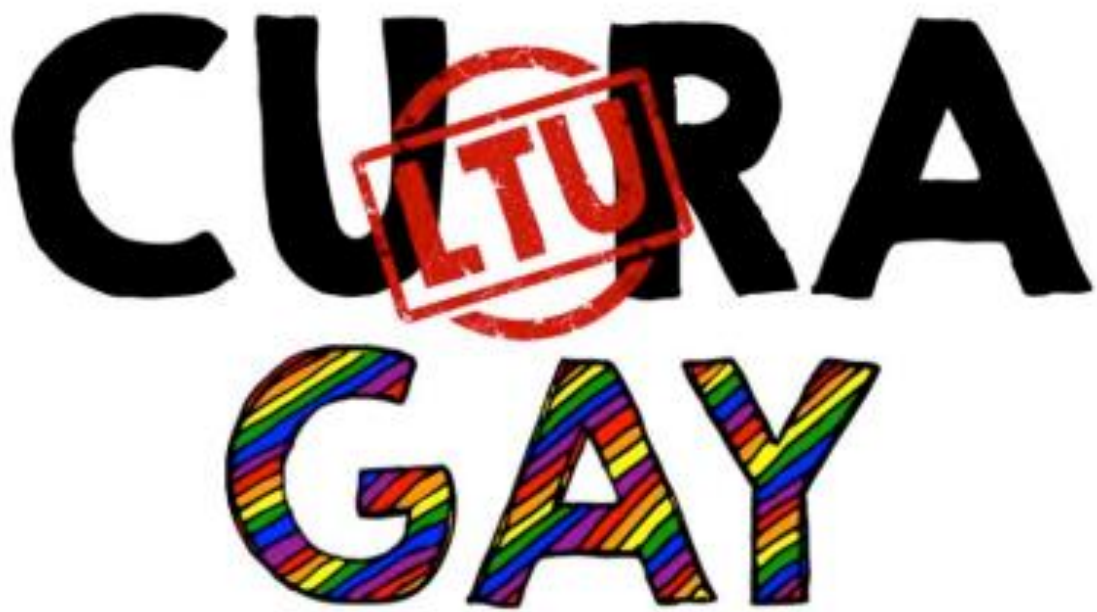

Fonte: Facebook, 2013.

A confecção desse cartaz - que transforma a "cura gay" em "cultura gay" aponta para uma forma de participação política diversa das práticas políticas juvenis de contextos anteriores. Atualmente, muitos jovens desconfiam dos canais formais de participação política, preferindo atuar fora deles. Segundo Carrano (2012),

uma das hipóteses mais correntes no debate sobre a participação contemporânea dos jovens é a que reconhece as novas formas da participação política dos jovens: o lugar da cultura, os agrupamentos em torno de novas temáticas relacionadas ao campo simbólico, os usos da internet e redes sociais virtuais etc (CARRANO, 2012, p. 93).

Essa é a hipótese do estudo que serve de pretexto para esse artigo. Embora reconhecendo a necessidade de mais investigaçóes que apontem para a relação entre ciberativismo e participação política juvenil, não nos parece demais considerar que as ações dos jovens internautas aqui apresentadas sejam indícios dessa relação. Se, conforme Carrano (2012), os jovens tendem a se engajar mais em causas do que em instituições e necessitam aderir a ações coletivas que lhes permitam controlar os processos decisórios, cujos resultados não sejam postergados para um futuro longínquo, tudo indica que as redes sociais digitais, promotoras da interlocução entre os sujeitos no momento em que o individualismo se torna cada vez mais possessivo, possam favorecer a participação política da juventude. 
Ao levarem o cartaz "cultura gay" para as ruas, durante as manifestaçôes, os jovens apontam para a relação indissociável entre os processos comunicacionais digitais e os espaços urbanos, mostrando o quanto hoje os movimentos sociais engendrados pelas práticas imersas na cibercultura não se limitam à internet, uma vez que também há a necessidade de a mobilização tornar-se "visível nos lugares da vida social" (CASTELLS, 2013, p. 15). Segundo o autor, "é por isso que [os movimentos sociais] ocupam o espaço urbano e os prédios simbólicos. Os espaços ocupados têm desempenhado papel importante na história da mudança social" (CASTELLS, 2013, p. 15). Nesse sentido, o que o estudo vem demonstrando é que os novos cenários, circunscritos pelos efeitos econômicos, sociais e culturais da globalização e pela configuração da sociedade em rede sugerem aos segmentos juvenis outros caminhos para agir e resistir.

Um dos caminhos que parece se abrir para o protagonismo juvenil é o da imersão na cibercultura, que amplia a capacidade de participação política através da mediação do diálogo em rede, proporcionando o envolvimento de muitos internautas, geograficamente dispersos, em torno de práticas sociais de interesse comum. Para Castells (2013), os movimentos sociais na era da internet atuam de forma que novos espaços híbridos sejam construídos pelos manifestantes: "conectando o ciberespaço com o espaço urbano numa interação implacável e constituindo, tecnológica e culturalmente, comunidades instantâneas de prática transformadora" (CASTELLS, 2013, p. 16). As transformações desencadeadas pelas práticas sociais ciberculturais mostra a força política dos pensamentos veiculados às inúmeras imagens digitais produzidas por pessoas amadoras, cuja facilidade de circulação é proporcionada pelas dinamicidades comunicacionais da internet (JENKINS, 2009).

A conversa online entre os jovens Jorge, Feliciana, Thayane, Rodrigo, Patrick, Nogan, Nectar, Polobio e Dilton, que resultou na politização da proposta homofóbica da "Cura Gay", aponta para o caráter colaborativo das redes sociais, indispensável a que, mesmo à distância, todos tenham se envolvido taticamente na construção do cartaz de protesto contra a homofobia. Isso porque os conteúdos digitais (imagem, texto, som) "podem ser manipulados infinitamente, dependendo unicamente de decisóes que cada interagente toma ao lidar com seus periféricos de interação como mouse, tela tátil, joystick, teclado" (SILVA, 2008, p. 71). O crescente interesse pela aquisição das diversas tecnologias digitais, principalmente entre as pessoas mais jovens, emerge da necessidade de sentirem-se como produtores de 
cultura na interconexão com o outro (todos-todos), e não mais apenas como meros receptores de informaçáo emitidas pelos meios de comunicação massivos (um-todos). Isso é o que mostra Okada (2011), ao afirmar que a internet rompe com o "paradigma de 'transmissão' e 'passividade" (OKADA, 2011, p. 10) ao oferecer a seus usuários interfaces abertas para processos de cunho educativo colaborativos e coautorais.

Primo (2013) realiza inúmeras reflexóes sobre a cibercultura e ressalta que, com a emergência das tecnologias de comunicação e informação, as práticas ativistas se beneficiaram das dinâmicas comunicacionais das redes sociais da internet. Não há dúvida de que buscar estabelecer formas de dialogar sobre todo e qualquer tipo de tema, indo dos mais corriqueiros do dia a dia aos mais polêmicos, como o projeto "cura gay", é reconhecer o protagonismo atual dos jovens brasileiros para expressarem suas ideias, opiniôes, anseios e angústias, reforçando a ideia de que não podemos.

Ignorar a força dos movimentos espontâneos em rede, cujos efeitos antes não eram possíveis em uma sociedade caracterizada pela mídia de massa. As próprias práticas de ciberativismo comprovam a força dos meios digitais para a articulação, mobilização e açóes políticas (PRIMO, 2013, p. 17).

A participação e o engajamento político dos jovens na confecção do cartaz foram potencializados pelas práticas sociais ciberculturais, cujos processos comunicacionais promovem formas dinâmicas de interagir com o outro através da internet. Com o imenso fluxo de informação que circula livremente hoje pela rede mundial de computadores,

cada vez mais as pessoas têm ideias originais e cooperam para comunicálas, avaliá-las, testá-las, realizá-las. Desde que uma ideia é concebida, ela torna-se pública, ela entra em competição cooperativa no ciberespaço com outras ideias (LEMOS e LÉVY, 2010, p. 44).

Foi esse o caminho que gerou a produção do cartaz "cultura gay". A ideia inicial de Jorge no Facebook ("bunitos, acabei de fazer essa imagem para a manifestação de amanhã”), aliada ao desejo dele de aprimorá-la a partir do diálogo em rede com outros internautas ("queria a opinião de vocês. curtiram, não curtiram e pq?”) possibilita compreender como o compartilhamento da ideia, e seu acabamento pela cooperaçáo dos jovens interlocutores de Jorge no Facebook, acabou por gerar a participação política dos mesmos. 
A participação colaborativa de diversos internautas na produção do cartaz implica no desafio de não mais se pensar que a realização de uma atividade online é de um só autor, mas de vários autores, o que confere à atividade uma dimensão colaborativa e coautoral. Entendendo o ciberespaço "como um potencializador de infinitas ações interativas, um novo espaço de comunicação, de sociabilidade, de reconfiguração e de autorias" (SANTOS e SANTOS, 2012, p. 162), não há como desconsiderar a reconfiguração permanente de informaçôes produzidas e compartilhadas entre os seres humanos através das dinâmicas comunicacionais digitais. Dessa forma, a "minha" ideia passa a ser "nossa" e adquire novos sentidos na medida em que essa ideia, que já não é mais "minha", é compartilhada e indefinidamente editada nas redes sociais da internet.

A troca colaborativa, característica das práticas sociais dos contextos digitais, nos auxiliam a perceber como o ciberativismo vem se organizando e adquirindo mobilização considerável entre as juventudes brasileiras. No caso específico dos jovens participantes da pesquisa, eles buscam no diálogo em rede estratégias de luta e resistência contra práticas preconceituosas e discriminatórias vivenciadas cotidianamente. Vale ressaltar que muitos desses jovens constituem-se como ciberativistas através das práticas sociais mediadas pelas tecnologias digitais, encontrando na internet a possibilidade de denunciar páginas do próprio Facebook que incitam discursos de ódio contra as chamadas "minorias" sociais, conforme analisaremos a seguir.

\section{"Alguém por favor denuncia e repassa?"5}

O cenário sociopolítico contemporâneo vem adquirindo novos contornos devido à interconexão das pessoas à uma mesma rede hipertextual gigantesca, a Web. $\mathrm{O}$ engajamento e a participação política dos jovens na internet ocorre porque há o que Pretto (2010) denominou de cultura da liberdade, cujas características são "a generosidade, a colaboração, a ética, o compartilhamento, a capacidade de ouvir para pode interagir" (PRETTO, 2010, p. 159). Atravessada por relaçóes de poder, essa cultura da liberdade vem permitindo aos sujeitos da pesquisa arquitetar estratégias de resistência preocupadas em questionar as normas $\mathrm{e}$ as hierarquias de gênero responsáveis pela produçáo das marcas da abjeção. Vale lembrar aqui os dizeres de

5 Expressáo de Nogan, um dos participantes da pesquisa, sobre a necessidade de que o grupo no Facebook se manifeste em torno de uma página que prega discursos homofóbicos. 
166 | Dilton Ribeiro do Couto Junior e Maria Luiza Magalhães Bastos Oswald

Foucault (2004, p. 277), para quem "se há relações de poder em todo o campo social, é porque há liberdade por todo lado".

Nossa intenção aqui não é analisar o conteúdo incitador de preconceitos, presente nas páginas do Facebook, bem como nos links referidos nas conversas dos pesquisados trazidas abaixo, mas apontar como o processo de denúncia vem sendo realizado na internet pelos jovens da pesquisa. Reconhecemos a legitimidade dessas denúncias realizadas pelos sujeitos porque, segundo argumenta Recuero (2013), a conversação em rede é um espaço fértil para a constituição de discussóes agressivas, ofensivas e propagaçáo da violência. A partir de incontáveis dizeres discriminatórios e preconceituosos amplamente difundidos na internet, diversos grupos sociais são inferiorizados pela cor da pele, orientação sexual, gênero e classe. As três conversas a seguir foram entabuladas no grupo do Facebook em (1) julho de 2013, (2) setembro de 2013 e (3) agosto de 2014 e revelam que o discurso de ódio dirigido às chamadas "minorias" sociais vêm encontrando espaço fértil em diversas páginas no Facebook, que difundem valores morais em sintonia com o racismo e a homofobia, para citar alguns. 
1

Nogan: Alguém por favor denuncia e repassa a página do Facebook https://www.facebook.com/Gayzismo

Polobio: Denunciei!

Nogan: Eu tive a infelicidade de comentar, recebi as respostas e estou denunciando novamente. Não vou ficar promovendo a pagina

Dilton: Gente, esta página é fichinha comparada com a Orgulho Hétero [https://www.facebook.com/OrgulhoHeteroBR?fref=ts]!

Estou acompanhando de perto as postagens e fico bastante assustado com o que leio nela.

Polobio: periodicamente eu denuncio a página do Orgulho hétero no Facebook.

Dilton: Eu penso que denunciar é preciso mesmo! Mas mesmo se denunciarmos o suficiente para tirar a página do ar, as pessoas vão continuar pensando coisas horrorosas sobre os homossexuais, só que fora da rede (ou certamente arranjaráo outro jeito de continuar com mensagens preconceituosas contra os gays)... eu penso que buscar uma aproximação com essas pessoas seja mais produtivo do que tirar a página do ar... o que voces acham?

Brandon Stark: eu acharia mais válido do que denunciar a página é mandar a página para a policia federal no site deles pra iniciarem uma investigação e prenderem potenciais neonazistas.

2

Nogan: "Mulheres são seres puramente sexuais". denunciado. Sugiro que todos façam o mesmo. http://homemdebem.org/mulheres-sao-serespuramente-sexuais/

Para quem ainda não conhece: site da Safernet do Brasil para crimes humanos na internet: http://www.safernet.org.br/site/denunciar ${ }^{6}$

Jorge: denunciei!

Dilton: me too. Barbaridade o que o pessoal posta na rede! :/

\footnotetext{
${ }^{6}$ De acordo com as informaçóes do site http://www.safernet.org.br/site/denunciar, a "SaferNet Brasil oferece um serviço de recebimento de denúncias anônimas de crimes e violaçóes contra os Direitos Humanos na Internet, contanto com procedimentos efetivos e transparentes para lidar com as denúncias. Além disso, contamos com suporte governamental, parcerias com a iniciativa privada, autoridades policiais e judiciais, além, é claro, de você usuário da Internet. Caso encontre imagens, vídeos, textos, músicas ou qualquer tipo de material que seja atentatório aos Direitos Humanos, faça a sua denúncia]”. Acesso em: 20 ago. 2014.
} 
3

Dalton: "Jovem negra coloca foto com namorado branco no Facebook e sofre racismo" :/ Eis a reportagem:

http://noticias.uol.com.br/cotidiano/ultimasnoticias/2014/08/28/jovem-negra-coloca-foto-com-namorado-brancono-facebook-e-sofre-racismo.htm

Cara pessoas da idade dessa menina 20a, nasceram em 1994!!! Eu ja tinha 10 e a escravidão ja tinha acabado fazia tempo! Como podem desferir assim publicamente palavras de tal ódio e conteúdo?! *choro.

Dilton: Dalton, eu vi aquela foto dos namorados! é muita crueldade mesmo, e a internet é um prato cheio para propagar esse tipo de preconceito/discriminação (vide a página do Facebook "\#Orgulho de ser hetero", que hoje em dia, agosto de 2014, já tem cerca de 1 milhão e 700 mil curtidas - ou seja, pessoas acompanhando a página).

Dalton: Eu entrei la e denunciei como ofensiva a página, ja tem tempo acho q vou fazer outra vez! Devíamos todos fazer e mandar os amigos tb denunciarem.

Dilton: [...] Eu lembro que o Polobio disse que denunciava essa página constantemente. Eu já denunciei algumas vezes... mas ao mesmo tempo fico me perguntando: a gente denuncia e aí? Se tudo der certo como a gente quer, a página acaba. Mas precisamos lembrar que as relaçóes na internet são dinâmicas e não é difícil criar outras páginas semelhantes. Claro que sou contra este tipo de página que prega dizeres horríveis! Mas eu acho mais produtivo interagir com o povo dessas páginas horríveis e tentar plantar algumas boas ideias do que simplesmente "denunciar para acabar". Eu acho que antes de enfrentar os dizeres homofóbicos/racistas, é preciso conhece-los melhor, conhecer essas pessoas que têm tanto ódio no coração, e nada como ver tudo isso nessas páginas horríveis. Eu li muita coisa navegando no "\#Orgulho de ser hetero" [...]

Dalton: Fui lá agora e não vi post homofóbicos, mas sim machistas.

Dilton: Isso mesmo! Mas já salvei várias conversas de lá no meu computador. Inclusive em uma das discussóes que participei, eu defendi o direito dos homossexuais e me disseram coisas horríveis (incluindo um monte de palavrôes).

Dalton: [resposta do Facebook após a denúncia da página] Obrigado por dedicar tempo para comunicar algo que você acha que possa violar a nossa comunidade. Relatórios como o seu são uma importante parte do que torna o Facebook um ambiente seguro e acolhedor ${ }^{7}$.

7 Tradução de: "Thank you for taking the time to report something that you feel may violate our Community Standards. Reports like yours are an important part of making Facebook a safe and welcoming environment". 
As diferentes estratégias encontradas pelos jovens para concretizar suas ações de denúncia na internet nos permite visualizar uma nova forma de fazer política envolvendo pessoas geograficamente dispersas sem a necessidade da organização burocrática e hierárquica, segundo apontam Lemos e Lévy (2010). De acordo com os autores, as manifestaçóes online, constituídas por grupos de diferentes tamanhos e com objetivos e interesses diversos, são "organizadas pelo medium planetário por excelência que é a Internet (LEMOS e LÉVY, 2010, p. 160, grifo nosso). Eles corroboram a ideia de que, com a internet, "Estamos 'entre nós" (LEMOS e LÉVY, 2010, p. 170), cada vez mais interconectados e pensando de forma colaborativa numa mesma rede.

Segundo as conversas online evidenciam, a mobilização política não esgota seus esforços na mera denúncia de determinadas páginas da internet, mas há o desejo pelo envolvimento e conscientização de um maior número possível de pessoas em torno daquilo que se denuncia. Isso fica claro nos dizeres de Nogan, ao pontuar: "Alguém por favor denuncia e repassa?" e "denunciado. Sugiro que todos façam o mesmo". "Repassar" ou "compartilhar" significa que não é a intenção de Nogan limitar o ato político da denúncia aos integrantes do grupo, e sim que a repercussão desta ação seja amplamente divulgada em outras redes sociais. As manifestaçôes políticas online vêm reconhecendo a Web não como mero espaço para produção e distribuição de bits, mas "como elemento de fortalecimento dos processos de produção de culturas e de conhecimentos" (PRETTO e RICCIO, 2010, p. 160).

As diversas estratégias políticas de resistência encontradas nas práticas dos jovens pesquisados remetem para uma concepção de pesquisa que se identifica com a ótica bakhtiniana de concepção de sujeito e de mundo. Tal concepção, que atribui relevância social e política à pesquisa em Ciências Humanas, propõe ao pesquisador reconhecer que "minha posição no mundo, num dado tempo, num dado lugar, me confere responsabilidade. Sou responsável por realizar aquilo que é próprio do meu lugar, da minha condição concreta e única” (AMORIM, 2013, p. 34). Desse modo, pesquisador e sujeitos, participando de forma cúmplice do ato de "denunciar" e "repassar" acontecimentos que revelam discriminação e preconceito percebidos e vivenciados na internet, convidam outros sujeitos a engajarem-se ética e politicamente no enfrentamento às intolerâncias sociais. 


\section{Algumas breves palavras finais}

O discurso é objeto de desejo, traduz as lutas e o poder dos quais almejamos nos apoderar, segundo Foucault (1999). Com isso em mente, percebemos a importância dos grupos online nas redes sociais da internet que se constituem também com a intenção de contestar os discursos que produzem determinadas verdades, como aquelas que naturalizam e normatizam a heterossexualidade e desqualificam os sujeitos apontados e rotulados como "desviantes" das normas sociais que regulam as condutas esperadas para os gêneros. Os sujeitos vêm ocupando o Facebook e mobilizando-se politicamente na rede no combate às diferentes formas com as quais os gêneros, as sexualidades e os corpos são normatizados e classificados por determinados atributos socialmente construídos que reforçam hierarquizaçôes e, consequentemente, desqualificações dos seus modos de ser e estar no mundo.

O diálogo em rede fortalece a interação entre as chamadas "minorias" sexuais, promove a possibilidade de resistência frente à heteronormatividade a partir de ativismos que se constituem livre e dinamicamente através das práticas sociais da cibercultura. Essas práticas se tornaram evidentes na confecção colaborativa do cartaz e nas inúmeras denúncias que também vêm sendo realizadas pelos jovens no Facebook com o objetivo de expor ideologias que reforçam diferentes formas de preconceito e discriminação. Somando-se a isso, a mobilização e organização política dos jovens da pesquisa através dos processos comunicacionais digitais favorece também a

apropriação criativa dos meios tecnológicos de produção de informação, acompanhado de um forte repensar dos valores, práticas e modos de ser, pensar e agir da sociedade, o que implica na efetiva possibilidade de transformação social (PRETTO e ASSIS, 2008, p. 82).

Considerando que ainda vivemos em um contexto sociocultural no qual imperam discursos e práticas sociais sintonizadas com a ótica heteronormativa, vale ressaltar mais uma vez a importância das redes sociais da internet como espaços potentes na promoção de resistência e ativismo em prol da reivindicação por condiçóes mais humanas e dignas de existência. Os discursos preconceituosos e discriminatórios dirigidos a determinados grupos sociais adquirem maior visibilidade com as práticas ciberculturais em rede, o que torna imprescindível apropriarmo-nos cada vez mais das redes digitais para contestar e desarticular esses mesmos discursos.

Entendendo que "uma característica distintiva da mente humana é a capacidade de imaginar o futuro, a esperança é um ingrediente fundamental no apoio 
à ação com vistas a um objetivo" (CASTELLS, 2013, p. 18). Sendo assim, parece possível discernir que os participantes da pesquisa, ao adotarem o Facebook como lócus de resistência, fortalecendo os vínculos sociais e a mobilização coletiva, estejam exercendo a esperança de imaginar um futuro outro identificado com o compromisso ético-político com o enfrentamento da heteronormatividade e com a denúncia às abjetas formas de preconceito.

Dilton Ribeiro do Couto Junior é Pós-doutorando no Programa de Pós-Graduação em Educação da Universidade do Estado do Rio de Janeiro (ProPEd/UERJ). Membro do Grupo de Pesquisa Infância, Juventude, Educação e Cultura (IJEC) e do Grupo de Estudos em Gênero e Sexualidade e(m) Interseccionalidades (Geni). E-mail: junnior_2003@yahoo.com.br.

- Maria Luiza Magalhães Bastos Oswald é Doutora em Educação pela Pontificia Universidade Católica do Rio de Janeiro (PUC - Rio). E Professora Associada da Faculdade de Educação e do ProPEd/UERJ. Lider do IJEC. E-mail: moswalduerj@yahoo.com.br.

\section{Referências}

ABRAMO, Helena Wendel. Considerações sobre a tematização social da juventude no Brasil. Revista Brasileira de Educação, n. 5-6, p. 25-36, 1997. Disponível em: <http://anped.tempsite.ws/novo_portal/rbe/rbedigital/RBDE05_6/RBDE05_6_05_HELENA_ WENDEL_ABRAMO.pdf>. Acesso em: 10 mar. 2015.

AMORIM, Marília. Para uma filosofia do ato: "válido e inserido no contexto". In: BRAIT, Beth (Org.). Bakhtin, dialogismo e polifonia. São Paulo: Contexto, 2013, p. 17-43.

BAKHTIN, Mikhail. Estética da criação verbal. Tradução de Paulo Bezerra. 6. Ed. São Paulo: Martins Fontes, 2011.

CARRANO, Paulo. A participação social e política de jovens no Brasil: consideraçóes sobre estudos recentes. O social em questão, Ano XV, n. 27, p. 83-99, 2012. Disponível em: <http://osocialemquestao.ser.puc-rio.br/media/OSocial27_Carrano1.pdf>. Acesso em: 20 fev. 2013.

CASTELLS, Manuel. Redes de indignação e esperança: movimentos sociais na era da internet. Tradução de Carlos Alberto Medeiros. Rio de Janeiro: Zahar, 2013.

CASTELLS, Manuel. Inovação, liberdade e poder na era da informação. In: Sociedade Midiatizada. MORAES, Dênis (Org.). Rio de Janeiro: Mauad, 2006, p. 225-231. 
COUTO JUNIOR, Dilton Ribeiro; OSWALD, Maria Luiza. Cibercultura, juventude e escritas de si: colocando em questão a heteronormatividade. In: OSWALD, Maria Luiza; COUTO JUNIOR, Dilton Ribeiro; WORCMAN, Karen (Orgs.). Narrativas Digitais, Memórias e Guarda. Curitiba: Editora CRV, 2014, p. 157-171.

DAYRELL, Juarez. O jovem como sujeito social. Revista Brasileira de Educação, n. 24, p. 40-52, set./out./nov./dez. 2003. Disponível em: <http:/www.scielo.br/pdf/rbedu/n24/n24a04 >. Acesso em: 10 jun. 2010.

FOUCAULT, Michel. A ordem do discurso. Tradução de Laura Fraga de Almeida Sampaio. 5. Ed. São Paulo: Editora Loyola, 1999.

FOUCAULT, Michel. Uma trajetória filosófica: para além do estruturalismo e da hermenêutica. Tradução de Vera Porto Carrero. Rio de Janeiro: Forense Universitária, 1995.

FOUCAULT, Michel. A ética do cuidado de si como prática da liberdade. In: MOTTA, Manoel Barros (Org.) FOUCAULT, Michel. Coleção Ditos \& Escritos V. Ética, sexualidade, política. Tradução de Elisa Monteiro e Inês Autran Dourado Barbosa. Rio de Janeiro: Forense Universitária, 2004, p. 264-287.

FREITAS, Maria Teresa de Assunção. Letramento digital e formação de professores. 2005, Caxambu. Anais da ANPOCS 2005. Caxambu: Espaço Livre, 2005, 16p. Disponível em: <www.28reuniao.anped.org.br/textos/gt16/gt16858int.rtf>. Acesso em: 25 ago. 2016.

GALLO, Sílvio; ASPIS, Renata Lima. Biopolítica-vírus e educação-governamentalidade e escapar e... Revista de Estudos Universitários (REU), Sorocaba, v. 37, n. 2, p. 167-179, dez. 2011. Disponível em: <http://periodicos.uniso.br/ojs/index.php/reu/article/view/651>. Acesso em: 10 jan. 2014.

JENKINS, Henry. Cultura da convergência. Tradução de Suzana Alexandria. 2. Ed. São Paulo: Aleph, 2009.

JOBIM E SOUZA, Solange; ALBUQUERQUE, Elaine Deccache Porto. A pesquisa em ciências humanas: uma leitura bakhtiniana. Bakhtiniana, São Paulo, v. 7, n. 2, p. 109-122, jul./dez. 2012. Disponível em: <http://www.scielo.br/pdf/bak/v7n2/08.pdf>. Acesso em: 15 set. 2015.

LEMOS, André. Os sentidos da tecnologia: cibercultura e ciberdemocracia. In: LEMOS, André; LÉVY, Pierre. O futuro da internet: em direção a uma ciberdemocracia planetária. São Paulo: Paulus, 2010, p. 21-31.

LEMOS, André. Cibercultura: tecnologia e vida social na cultura contemporânea. 6. ed. Porto Alegre: Editora Sulina, 2013.

LEMOS, André. Cibercultura como território recombinante. In: MARTINS, Camila Duprat; CASTRO E SILVA, Daniela; MOTTA, Renata (Orgs.). Territórios recombinantes: arte e tecnologias. São Paulo: Instituto Sérgio Motta, 2007, p. 35-48.

LEMOS, André. LÉVY, Pierre. O futuro da internet: em direção a uma ciberdemocracia planetária. São Paulo: Paulus, 2010.

LOURO, Guacira Lopes. Gênero e sexualidade: pedagogias contemporâneas. Pro-Posiçóes, Campinas, v. 19, n. 2, p. 17-23, maio/ago. 2008. Disponível em: <http://www.scielo.br/pdf/pp/v19n2/a03v19n2.pdf>. Acesso em: 10 maio 2015.

LOURO, Guacira Lopes. Foucault e os estudos queer. In: RAGO, Margareth (Org.); VEIGA-NETO, Alfredo (Org.). Para uma vida não-fascista. Belo Horizonte: Autêntica, 2009, p. 135-143. 
OKADA, Alexandra. Colearn 2.0 - coaprendizagem via comunidades abertas de pesquisa, práticas e recursos educacionais. Revista E-Curriculum, São Paulo, v. 7, n. 1, p. 1-15, abr. 2011. Disponível em: <https://revistas.pucsp.br/index.php/curriculum/article/view/5813>. Acesso em: 15 out. 2014.

PAIS, José Machado. A construção sociológica da juventude: alguns contributos. Análise Social, v. 25, p. 138-165, 1990. Disponível em: <http://analisesocial.ics.ul.pt/ documentos/1223033657F3sBS8rp1Yj72MI3.pdf>. Acesso em: 10 abr. 2017.

PRETTO, Nelson De Luca. Redes sociais e educação: o que quer a geração alt+tab nas ruas? Liinc em Revista, Rio de Janeiro, v. 10, n. 1, p. 344-350, maio 2014. Disponível em: <http://revista.ibict.br/liinc/article/view/3498/3021>. Acesso em: 15 jan. 2017.

PRETTO, Nelson De Luca. Professores universitários em rede: um jeito hacker de ser. Motrivivência, Florianópolis, ano XXII, n. 34, p. 156-169, jun. 2010. Disponível em: <https://periodicos.ufsc.br/index.php/motrivivencia/article/view/16038/15850>. Acesso em: 10 ago. 2011.

PRETTO, Nelson De Luca; ASSIS, Alessandra. Cultural digital e educação: redes já! In: PRETTO, Nelson De Luca; SILVEIRA, Sérgio Amadeu (Orgs.). Além das redes de colaboraçâo: internet, diversidade cultural e tecnologias do poder. Salvador: EDUFBA, 2008, p. 75-83.

PRETTO, Nelson De Luca; RICCIO, Nicia Cristina Rocha. A formação continuada de professores universitários e as tecnologias digitais. Educar em Revista, Curitiba, n. 37, p. 153-169, maio/ago. 2010. Disponível em: <http://www.scielo.br/pdf/er/n37/a10n37>. Acesso em: 15 abr. 2017.

PRIMO, Alex. Interaçóes mediadas e remediadas: controvérsias entre as utopias da cibercultura e a grande indústria midiática. In: PRIMO, Alex (Org.). Interaçóes em rede. Porto Alegre: Editora Sulina, 2013, p. 13-32.

RECUERO, Raquel. Atos de ameaça à face e à conversação em redes sociais da internet. In: PRIMO, Alex (Org.). Interaçôes em rede. Porto Alegre: Editora Sulina, 2013, p. 51-69.

RECUERO, Raquel; ZAGO, Gabriela; BASTOS, Marco Toledo. O discurso dos \#ProtestosBR: análise de conteúdo do Twitter. Galáxia, São Paulo, n. 28, p. 199-216, dez. 2014. Disponível em: <http://www.scielo.br/pdf/gal/v14n28/v14n28a17.pdf>. Acesso em: abr. 2017.

ROSA, Ana Carolina Pereira da Silva; FERREIRA, Helenice Mirabelli Cassino; OSWALD, Maria Luiza Magalhães Bastos. Práticas culturais juvenis: máscaras contemporâneas. Revista da FAEEBA, Salvador, v. 19, n. 33, p. 215-227, jan./jun. 2010. Disponível em: <http://www.uneb.br/revistadafaeeba/files/2011/05/numero33.pdf>. Acesso em: 25 maio. 2012.

SANTAELLA, Lucia. Intersubjetividade nas redes digitais: repercussões na educação. In: PRIMO, Alex. (Org.). Interaçôes em rede. Porto Alegre: Editora Sulina, 2013, p. 33-47.

SANTOS, Edméa Oliveira. Formação de professores e cibercultura: novas práticas curriculares na educação presencial e a distância. Revista da FAEEBA, v. 11, n. 17, p. 113-122, jan./jun. 2002.

SANTOS, Edméa. Educação on-line: a dinâmica sociotécnica para além da educação a distância. In: PRETTO, Nelson de Luca (Org.). Tecnologia e novas educaçóes. Salvador: EDUFBA, 2005, p. 194-202.

SANTOS, Rosemary; SANTOS, Edméa Oliveira. Cibercultura: redes educativas e práticas cotidianas. Revista Eletrônica Pesquiseduca, v. 4, n. 7, p. 159-183, jan./jul. 2012. Disponível em: <http://www.ufjf.br/grupar/files/2014/09/Formacao_de_ professores_e_Cibercultura.pdf>. Acesso em: 5 abr. 2016. 
174 | Dilton Ribeiro do Couto Junior e Maria Luiza Magalhães Bastos Oswald

SILVA, Marco. Cibercultura e educação: a comunicação na sala de aula presencial e online. Revista FAMECOS, Porto Alegre, n. 37, p. 69-74, dez. 2008. Disponível em: $<$ http://revistaseletronicas.pucrs.br/ojs/index.php/revistafamecos/article/view/4802/3606>. Acesso em: 20 mar. 2017.

Texto recebido em 05 de julho de 2017. Aprovado em 21 de julho de 2017. 